\title{
MECANISMOS DE INSTITUCIONALIZAÇÃO DA ATIVIDADE JURÍDICA: PRESSUPOSTOS SOCIOLÓGICOS PARA ANÁLISE LINGÜÍSTICA
}

\author{
Cristiane Fuzer \\ crisfuzer@via-rs.net
}

\section{RESUMO}

Considerando-se a perspectiva de linguagem que se insere nos estudos da Análise Crítica do Discurso, em que se analisam aspectos sócio-culturais que vão além de estudos tradicionais de descrição e explicação de elementos lingüísticos, pretende-se, neste trabalho, verificar alguns mecanismos de institucionalização das atividades realizadas pelo grupo dos operadores do Direito, que desempenham papéis específicos perante os demais grupos sociais e, de certa forma, mantêm a ordem social. A partir do conhecimento dos mecanismos de institucionalização, segundo os pressupostos teóricos de Veblen (1980), Berger \& Luckmann (1985), Pross (1980), Elias \& Scottson (2000), Bourdieu (1996), Fairclough (2003) e Bazerman (2004), busca-se depreender como os operadores do direito organizam e controlam suas atividades na sociedade e em que medida os textos que produzem ajudam a realizar tais atividades. Para isso, consideram-se textos que compõem os autos de um processo da Vara Criminal e de um processo da Vara Civil. A análise permitiu constatar que o processo penal pode ser considerado um sistema de gêneros que organiza o sistema de atividades típicas da instituição jurídica. As reflexões, realizadas à luz das teorias sociológicas estudadas, possibilitam perceberem-se algumas razões pelas quais a linguagem utilizada nos textos utilizados por esse grupo social é considerada, muitas vezes, hermética pelos indivíduos de outros grupos.

\section{INTRODUÇÃO}

O indivíduo, enquanto ser social, está cercado de simbolismos. A linguagem, como uma das modalidades simbólicas, converte-se para o indivíduo em ponto de partida do seu pensamento e serve como mediação nas relações sociais. Se admitirmos que o homem vive não só no mundo natural, mas em um mundo simbólico, conforme supôs Ernst Cassirer, citado por Pross (1974), então é coerente considerar que cada sujeito tem uma representação do que seja o mundo (o mundo é o que lhe parecer ser). A constituição dessa representação é propiciada principalmente pela linguagem.

O indivíduo age e interage, no mundo, com base em símbolos que, segundo Berger \& Luckmann (1985), Ihe são dados, uma vez que, ao nascer, já passa a fazer parte um determinado grupo social. À medida que se desenvolve, o indivíduo pode ser inserido em alguns grupos e, concomitantemente, excluído de outros, e isso é determinante nas relações que poderá ter com indivíduos do mesmo grupo e/ou de grupos diferentes à medida que reconhecer os símbolos que caracterizam cada grupo. A linguagem faz parte desse sistema de símbolos que constituem a complexa rede social em que os indivíduos se imbricam e estabelecem relações de poder.

O uso da linguagem é norteado por mecanismos de institucionalização, que são mobilizados pelos indivíduos para organizarem-se enquanto um grupo específico que busca reservar seu espaço na sociedade, que busca formar e manter uma identidade a fim de 
ser reconhecido pelos membros de outros grupos e, assim, passar a estabelecer relações de poder.

Essa visão sociológica da linguagem, a partir dos trabalhos de Veblen (1980), Berger \& Luckmann (1985), Pross (1980), Elias \& Scotson (2000), Bourdieu (1996) ${ }^{1}$, Fairclough (2001) e Bazerman (2004), norteará este trabalho, que pretende fazer algumas reflexões sobre os mecanismos de institucionalização utilizados por um grupo entre tantos que formam a complexa rede social que constitui o mundo simbólico em que vivemos: o grupo dos operadores do Direito.

Dessa forma, buscam-se subsídios que possibilitem o encaminhamento de análise de textos segundo os propósitos da Análise Crítica do Discurso, que, segundo Heberle (2000, p. 290-1), consiste em "uma área multidisciplinar de estudos da linguagem, voltada para a investigação de fenômenos discursivos diversos". Pesquisadores da área (FAIRCLOUGH, 2001 e 2003, MEURER \& MOTTA-ROTH, 2002, dentre outros) procuram demonstrar como "representações lingüísticas são afetadas por valores sociais e como determinadas visões da realidade preponderam em detrimento de outras". As relações entre texto, sociedade, poder e cultura são consideradas pelos pesquisadores dessa linha, que analisam aspectos sócio-culturais que vão além de estudos tradicionais de descrição e explicação de elementos lingüísticos.

Nessa perspectiva, discurso "é o conjunto de afirmações que, articuladas através da linguagem, expressam os valores e significados das diferentes instituições" (MEURER in MEURER \& MOTTA-ROTH, 1997, p. 16). Essa definição tem sua fundamentação no ponto de vista de Fairclough (2001, p. 90), que propõe o conceito de discurso a partir da consideração do "uso da linguagem como uma forma de prática social, e não como atividade puramente individual ou reflexo de variáveis situacionais". O discurso é, portanto, em linhas gerais, um modo de ação, "uma forma em que as pessoas podem agir sobre o mundo e especialmente sobre os outros, como também um modo de representação" (FAIRCLOUGH, 2001, p. 91).

Considerando essa perspectiva de análise, um dos objetivos deste trabalho é identificar alguns mecanismos de institucionalização da classe jurídica, que tem um papel tão legitimado na sociedade a ponto de seus membros serem freqüentemente requisitados pelos indivíduos de todos os outros grupos quando estes se vêem na necessidade de defender-se, decorrente de conflitos que perpassam a vida em sociedade.

A partir do conhecimento dos mecanismos de institucionalização, busca-se depreender como os operadores do direito organizam e controlam suas atividades na sociedade, a partir da utilização de certos gêneros textuais/discursivos ${ }^{2}$, cujos critérios determinam a maneira como elaboram seus textos. Com base nessa análise, é possível também encontrar razões para a linguagem utilizada nesse grupo ser considerada, muitas vezes, hermética pelos indivíduos de outros grupos sociais.

\footnotetext{
${ }^{1}$ As obras de Veblen, Berger \& Lukmann, Pross, Elias \& Scotson e Bourdieu foram publicadas pela primeira vez, respectivamente, em 1899, 1966, 1974, 1965 e 1968.

${ }^{2}$ Tendo em vista as discussões em torno das terminologias "gênero textual" (proposta por MEURER, 2001) e "gênero do discurso" (proposta por BAKHTIN, na década de 1950) no meio acadêmico, opto por utilizar o termo "gêneros textuais/discursivos" neste trabalho, por entender a inter-relação de texto e discurso inerente à noção de gêneros.
} 


\section{REFERENCIAL TEÓRICO}

\subsection{Mecanismos de institucionalização - abordagem sociológica}

O ser humano exterioriza-se continuamente na atividade, a qual produz a ordem social. Essa tese, defendida por Berger \& Luckmann (1985), sustenta-se na idéia de que toda atividade humana está sujeita ao hábito, o que implica a recorrência de ações moldadas em um padrão que pode ser reproduzido com economia de esforço.

Segundo esses sociólogos, o hábito reduz a uma única as várias maneiras que o ser humano tem de realizar um projeto. A formação do hábito estreita as opções e, com isso, liberta o indivíduo da carga psicológica de ter de tomar decisões em todo momento e, ao economizar esforço, libera energia para decisões que podem ser necessárias em ocasiões menos previsíveis. Reconhecendo que o ser humano não consegue viver isoladamente, Berger \& Luckman afirmam que a ordem social existe apenas como produto da atividade humana. E "toda atividade está sujeita ao hábito" (p.76-77).

Quando ocorre uma tipificação recíproca de ações habituais por tipos de atores, tem-se o que os sociólogos chamam de institucionalização. Num grupo particular, as tipificações das ações habituais são acessíveis a todos os membros desse grupo. Outro aspecto da institucionalização apontado por Berger \& Luckmann (1985) é a historicidade. As tipificações recíprocas das ações não são criadas instantaneamente; elas são construídas no curso de uma história compartilhada pelos membros do grupo. A partir do momento que uma instituição se forma pela recorrência de ações tipificadas por atores ao longo do tempo, ela passa a controlar a conduta humana. Para Berger \& Luckmann (1985), "dizer que um segmento da atividade humana foi institucionalizado já é dizer que este segmento da atividade humana foi submetido ao controle social" ( $p$. 80). Para Pross (1980), a repetição, a duração e a ritualização contribuem para manter a ordem social.

Desse modo, é possível um sujeito apropriar-se dos reiterados papéis realizados por outro sujeito, fazendo deles os modelos de seu próprio desempenho. Com isso, surge uma coleção de ações reciprocamente tipificadas, "tornadas habituais para cada qual em papéis, alguns dos quais se realizarão separadamente e outros em comum" (BERGER \& LUCKMANN 1985, p. 82).

A vantagem desse processo, segundo Berger \& Luckmann (1985), é o fato de os indivíduos que compartilham ações terem a capacidade de cada um predizer as ações do outro; a interação torna-se "predizível". Assim, entre os membros do grupo que compartilham as ações tipificadas, cada ação de um não será mais fonte de espanto e perigo potencial para o outro.

Mas, para isso, será preciso compartilhar da rotina, das atividades ritualizadas, dos papéis típicos da instituição. Os papéis, segundo Berger \& Luckmann (1985), representam a ordem institucional. Nesse sentido, "empenhar-se em julgar é representar o papel de juiz" (p. 104), uma vez que o indivíduo no exercício desse papel não está agindo "por sua própria conta", mas, sim, segundo os preceitos da instituição que ele representa. 
Para atuar em seus respectivos papéis, os indivíduos, segundo Berger \& Luckmann (1985), utilizam a linguagem e, também por meio dela, representam a instituição em realidade. A linguagem (desde as designações verbais até as simbolizações) também representa a instituição. Na perspectiva sociológica de Bourdieu (1996, p. 24), as trocas lingüísticas não são apenas relações de comunicação por excelência, mas também relações de poder simbólico em que se atualizam as relações de força entre os locutores ou seus respectivos grupos, em que ocorre o relacionamento operado, consciente ou inconscientemente, pelos locutores entre o produto lingüístico oferecido por um locutor socialmente caracterizado e os produtos simultaneamente propostos num espaço social determinado.

Com relação ao significado das palavras, é pertinente o ponto de vista de Bourdieu (1996), segundo o qual não existem palavras neutras, inocentes. Cada palavra pode assumir dois sentidos (até mesmo antagônicos) conforme a maneira que o emissor e o receptor tiverem de interpretá-la. Nesse sentido, a ciência social atenta para a autonomia da língua. "Não há nada que não se possa dizer, e pode-se dizer o nada" (Idem, p. 28).

Com relação à especialidade dos integrantes do grupo, Berger \& Luckmann (1985) explicam que, em virtude dos papéis que desempenha, o indivíduo é introduzido em áreas específicas do conhecimento socialmente objetivado, não só no sentido cognoscitivo e do conhecimento de normas, mas também dos valores e até mesmo das emoções.

A partir dessas constatações, Berger \& Luckman (1985, p. 107) concluem que

Aprender um papel não é simplesmente adquirir as rotinas que são imediatamente necessárias para o desempenho 'exterior'. É preciso que seja também iniciado nas várias camadas cognoscitivas, e mesmo afetivas, do corpo de conhecimento que é diretamente e indiretamente adequado a este papel.

A linguagem como uma maneira de constituir a instituição pode ser ainda evidenciada pela noção de signos proposta por Pross (1980, p. 69). Segundo esse autor, "algo é o que representa". O signo em lugar de algo é sempre e também um signo de alguém, ou seja, o signo em lugar de alguma coisa dirigida a um terceiro e o signo de alguém remetente a seu criador. Isso faz o signo digno de conservação. Isso pode ser percebido no âmbito do Direito. Segundo Pross (1980), a lei e os tratados estão em representação de relações que se dão mediante elos; estes se perdem, se não forem reconhecidos nem se impuserem sua função simbólica.

Existe um conjunto de diferenças associadas a diferenças sociais, que se revelam pertinentes do ponto de vista do sociólogo por fazerem parte de um sistema de oposições lingüísticas que é a retradução de um sistema de diferenças sociais. Sob o ponto de vista da sociologia, falar é "apropriar-se de um ou outro dentre os estilos expressivos já constituídos no e pelo uso, objetivamente marcados por sua posição numa hierarquia de estilos que exprime através da sua ordem a hierarquia dos grupos correspondentes" (BOURDIEU, 1996, p. 41). Segundo Bourdieu, esses estilos marcam aqueles que deles se apropriam. Locutores desprovidos de competência legítima se encontram excluídos dos universos sociais onde ela é exigida. 
Essa perspectiva pode ser, de certa forma, à noção de "estabelecidos e outsiders", segundo constatações de Elias \& Scotson $(2000)^{3}$. Os estabelecidos correspondem aos membros de um grupo que está bem instalado em posições de poder; demonstram-se orgulhosos de sua posição e compartilham costumes e convenções que garantem a alta coesão do grupo. Já os outsiders correspondem aos membros do grupo que, direta ou indiretamente, é excluído, discriminado e estigmatizado pelos estabelecidos, por representarem uma ameaça à ordem estabelecida.

Para manter-se na posição de estabelecidos, o grupo faz uso, ainda, de portadores de símbolos, os quais, segundo Pross (1980), mantêm a ordem. Os portadores podem ser pessoas transportadas para operar na qualidade de poder físico ou psíquico e representar a atualidade e o caráter imediato do poder que está ausente. Para Bourdieu (1996), a competência legítima é a capacidade reconhecida a uma pessoa autorizada, uma "autoridade", de empregar, em ocasiões oficiais (formal) a língua legítima. O poder de convencimento depende da pronúncia e daquele que pronuncia (aspectos pragmáticos da linguagem).

Bourdieu (1996, p. 57) argumenta que propriedades não-lingüísticas também podem colocar o locutor legítimo em posição eminente e estruturam a interação através do espaço que tais propriedades (como vestuário, púlpito do padre, estrado do professor, tribuna e microfone do orador) Ihe impõem. Outros portadores de símbolos são os uniformes, certas cores, brasões.

\subsection{Sistema de atividades e sistemas de gêneros - abordagem sócio-lingüística}

Os mecanismos de institucionalização, conforme as teorias anteriormente apresentadas, embasam a noção de sistema de atividades, teoria proposta por Bazerman (2004, 2005). Segundo esse pesquisador, "uma maneira de coordenar melhor nossos atos de fala uns com os outros é agir de modo típico, modos facilmente reconhecíveis com realizadores de determinados atos em determinadas circunstâncias" (2005, p. 29). Essas formas de comunicação que seguem padrões razoavelmente estáveis com os quais as pessoas de um determinado grupo social estão familiarizadas emergem como "gêneros".

Bazerman (2005), seguindo a perspectiva de Bakhtin (2003), salienta que os gêneros são facilmente reconhecidos por algumas características textuais que sinalizam o tipo de mensagem. Em vista disso, os formatos padronizados direcionam as pessoas no sentido de qual informação apresentar e como apresentar e possibilitando-lhes antecipar melhor quais serão as reações das outras pessoas.

No entanto, Bazerman (2005, p. 31) apresenta um ponto de vista sobre gêneros que ultrapassa a identificação de características, ao constatar que

\footnotetext{
${ }^{3}$ Elias esclarece "processos sociais de alcance geral na sociedade humana - inclusive a mane ira como um grupo de pessoas é capaz de monopolizar as oportunidades de poder e utilizá-las para marginalizar e estigmatizar membros de outro grupo muito semelhante" (Stephen Mennel, em nota introdutória da obra Os estabelecidos e os outsiders), a partir de um estudo realizado por Scotson numa comunidade próxima de Leicester, no fim da década de 1950 e início da de 1960.
} 
a definição de gêneros como apenas um conjunto de traços textuais ignora o papel dos indivíduos no uso e na construção de sentidos, ignora as diferenças de percepção e compreensão, o uso criativo da comunicação para satisfazer novas necessidades percebidas em novas circunstâncias e a mudança no modo de compreender o gênero com o decorrer do tempo.

Para Bazerman (idem), os gêneros são parte de processos de atividades socialmente organizadas, são "tipos que as pessoas reconhecem como sendo usados por elas próprias e pelos outros". Os gêneros são "parte do modo como os seres humanos dão formas às atividades sociais".

Certos gêneros tipificam as atividades de determinados grupos sociais. Tipificação é o termo usado por Bazerman (2005, p. 29-30) para designar o "processo de mover-se em direção a formas de enunciados padronizados, que reconhecidamente realizam certas ações em determinadas circunstâncias, e de uma compreensão padronizada de determinadas situações". Essas formas padronizadas direcionam as pessoas a realizarem determinadas ações e a produzirem determinados textos dependendo das circunstâncias e dos objetivos a serem atingidos, ou seja, determinam quais informações serão apresentadas, o modo de apresentá-las (formato padrão "relativamente estável" - nos termos de BAKHTIN, 2003).

Com relação ao texto, Fairclough (2001) o define como "qualquer instância da linguagem em uso" (p. 3). Textos podem ter efeitos sobre a vida das pessoas, podem mudar conhecimentos, crenças, atitudes, valores. Para ter seus significados compreendidos, é preciso entender a relação entre os participantes do evento social de que o texto faz parte. Para Fairclough (2001, p. 23-25), textos são eventos sociais porque constituem ações situadas no tempo e no espaço; um texto corresponde à ocorrência de uma das práticas sociais possíveis organizadas e controladas pelas ordens do discurso, as quais, por sua vez, "são a organização social e o controle da variação lingüística" (p. 24). Textos são, portanto, realizações concretas (físicas) de práticas sociais situadas numa estrutura social (entidade abstrata que define um grupo de possibilidades - estrutura econômica, jurídica, acadêmica, etc.).

Bazerman (2005) define texto sob o ponto de vista de enunciado, que incorpora "atos de fala", baseando-se na teoria dos filósofos John Austin e John Searle. Nessa perspectiva, o ato de fala (o texto) é o resultado de "uma série de palavras ditas, no tempo apropriado, em circunstâncias apropriadas e pela pessoa apropriada" (p. 25).

Mas os gêneros tipificam não apenas a forma textual. Segundo Bazerman (2005, p. 31), os gêneros "são parte do modo como os seres humanos dão forma às atividades sociais". Para caracterizar a configuração dos gêneros e o seu enquadramento em organizações, papéis e atividades mais amplas, Bazerman propõe conceitos que se sobrepõem: conjunto de gêneros, sistema de gêneros e sistema de atividades.

Conjunto de gêneros corresponde à coleção de tipos de textos produzidos por um sujeito no exercício de uma atividade. A análise de um conjunto de gêneros possibilita catalogarem-se as atividades típicas de determinado profissional, as quais são necessárias para a realização do trabalho com competência.

Os diversos conjuntos de gêneros utilizados por pessoas que trabalham de modo organizado, considerando-se as relações padronizadas que se estabelecem na produção, 
circulação e uso dos textos, fazem parte de um sistema de gêneros. No sistema, um gênero segue um outro gênero numa seqüência regular, em um fluxo comunicativo típico de um grupo de pessoas. Num sistema de gêneros, os conjuntos de gêneros estão ligados e "circulam em seqüências e padrões temporais previsíveis" (BAZERMAN, 2005, p. 33).

O sistema de gêneros, por sua vez, faz parte de um sistema de atividades típicas de uma determinada instituição. A definição do sistema de gêneros de que as pessoas participam possibilita ao analista identificar um frame que organiza o trabalho, a atenção e as realizações dessas pessoas no exercício de suas atividades. Para Bazerman (2005), quando se considera o sistema de atividades junto com o sistema de gêneros, focaliza-se o que as pessoas fazem e como os textos ajudam a fazê-lo.

\section{ASPECTOS METODOLÓGICOS}

Após a sistematização dos pressupostos teóricos sob a perspectiva sociológica dos estudos da linguagem, parte-se para a identificação dos mecanismos de institucionalização dos estudos. Para isso, aliam-se as teorias sociológicas que embasam teorias de análise lingüística, partindo-se do pressuposto de que, para se analisarem criticamente discursos, é necessário se considerarem as relações entre texto, sociedade, poder e cultura.

Com o propósito de verificar como tais mecanismos corroboram para a institucionalização de atividades realizadas pelo grupo de operadores do Direito e visualizar-se a organização dessas atividades, são considerados aspectos gerais dos participantes do grupo (desde critérios para inserção do grupo até elementos simbólicos nãolingüísticos, como vestuário).

Para a análise dos sistemas de gêneros que configuram o sistema de atividades do grupo em análise, são considerados elementos textuais que constituem os autos de um processo da Vara Criminal e os de um processo da Vara Civil.

Desse modo, buscam-se relacionar aspectos não-lingüísticos e lingüísticos que possam fazer parte do processo de institucionalização do grupo de operadores de direito na sociedade.

\section{RESULTADOS E DISCUSSÃO}

Da observação de atividades realizadas por operadores do direito e da análise de textos que circulam nesse meio é possível verificarem-se alguns mecanismos de institucionalização sistematizados anteriormente.

Com relação à tipificação recíproca de ações habituais, segundo a teoria de Berger \& Luckmann (1985), pode-se dizer que a instituição jurídica faz uso desse mecanismo na medida em que segue um sistema de atividades organizadas (como a constituição dos autos de um processo criminal ou civil, o julgamento no tribunal do júri, os critérios para a abertura de um processo, a interpretação da lei), executadas por determinados 
atores (advogados, promotores, delegados, juízes), com conhecimento especializado para cumprir o seu papel no subuniverso social de que participam.

A historicidade - recorrência das ações tipificadas através dos tempos - é outro aspecto marcante do processo de institucionalização do grupo em análise. Para exemplificar, convém citar o contexto histórico do júri. Segundo Daher (2005),

com a feição mais aproximada da que conhecemos hoje, o júri originou-se na Inglaterra, no período sucessivo ao Concílio de Latrão. Remonta, entretanto, ao período áureo do direito romano. (...) Da França, disseminou-se por todo o continente. Data deste tempo o direito de dizer, por parte de um Juiz togado, se o réu devia ou não ser submetido ao crivo do julgamento popular. (...)

No Brasil, a instituição do júri data de 18 de junho de 1822 e se encarregava do julgamento dos crimes de imprensa. Em 1824, inserido na Constituição do Império, passou a integrar o Poder Judiciário. Pelo Código de Processo Criminal de 1832 e pela reforma de 1871, foi alterado em sua estrutura e competência. Mantido na Constituição de 1891 e nas sucessivas, até 1937, quando a Carta foi omissa sobre ele, razão que a fez vir a ser corrigida por um Decreto-Lei, o de № 167 de 5 de janeiro de 1938, o qual delimitava a soberania dos veredictos.

Ao longo do tempo, a lei que organiza o júri, na verdade um decreto-lei de no 3.689 (Código de Processo Penal), datado de 03 de outubro de 1941, sofreu algumas modificações. Esse decreto estabelece como competência privativa do Tribunal do Júri o julgamento dos crimes de homicídio, simples ou qualificado, o infanticídio, o aborto.

Aliados ao critério da historicidade, os papéis, segundo Berger \& Luckmann (1985), representam também a ordem institucional. Nesse sentido, "empenhar-se em julgar é representar o papel de juiz" (p. 104), uma vez que o indivíduo no exercício desse papel não está agindo "por sua própria conta", mas, sim, segundo os preceitos da instituição que ele representa. Além disso, esse papel relaciona-se com outros papéis (como a do promotor de justiça, do delegado, etc.), e todos eles compreendem a instituição da lei. O juiz atua, então, como representante dessa instituição perante a sociedade, ou seja, perante todos os outros grupos que constituem a rede social. É o caso, por exemplo, do advogado que, após comprovar competência para tal, segundo exigências da instituição jurídica (como exercer a advocacia por um tempo determinado, realizar concursos, freqüentar a escola de magistratura, etc.), é reconhecido como um juiz de Direito. Uma vez nesse papel, apropria-se das ações habituais que fazem parte do conjunto de atividades que caracterizam a instituição jurídica.

Com relação às trocas lingüísticas, a instituição da lei é, basicamente, representada pela linguagem legal, pelos códigos da lei (Código Civil, Código Penal, Código de Processo Penal), teorias da jurisprudência e pelas legitimações e suas normas em sistemas éticos (Código de Ética jurídico) e religiosos (não raras vezes princípios religiosos são utilizados como argumentos para justificar certos atos em julgamento).

A linguagem legal é constituída de uma série de termos que assumem significado específico no discurso jurídico, como, por exemplo, a palavra "seqüestrar": no Direito Processual, significa "apreender judicialmente bem em litígio"; já no Direito Penal, "privar alguém de sua liberdade de locomoção" (DAMIÃO \& HENRIQUES, 1997, p. 35). Interessante notar que esta última acepção também faz parte da linguagem usual dos demais grupos sociais, já que é comum na linguagem popular (especialmente na mídia) 
associar-se "seqüestrar" à violência praticada contra pessoas ("fulano foi seqüestrado", "fulano sofreu seqüestro relâmpago"). Já a primeira acepção, associada a objetos (bens), parece ter seu uso menos difundido na sociedade em geral. Disso é possível depreender que o grupo dos operadores do direito se organiza em grupos mais específicos ${ }^{4}$, com suas respectivas especialidades e, conseqüentemente, termos técnicos específicos (jargão) que estão mais ou menos presentes na linguagem comum. Uma hipótese para isso é o fato de crimes contra a vida, julgado pelo Direito Penal, poderem atingir todas as classes sociais, ao passo que crimes contra o patrimônio ocorrem principalmente nas classes mais favorecidas economicamente.

Dependendo do crime a ser julgado, certos especialistas, dentro do universo jurídico, são mobilizados (daí a divisão das atividades em Varas no fórum). Conforme Berger \& Luckmann (1985) explicam, em virtude dos papéis que desempenha, o indivíduo é introduzido em áreas específicas do conhecimento socialmente objetivado, não só no sentido cognoscitivo e do conhecimento de normas, mas também dos valores e até mesmo das emoções. Assim, ser juiz implica não só o conhecimento da lei e provavelmente de uma gama muito mais ampla de negócios humanos de repercussões jurídicas, mas também o conhecimento dos valores e atitudes julgados adequados a um juiz, e tais valores e atitudes se estendem até os que são considerados convenientes para a esposa de um juiz, por exemplo. Ademais, o juiz deve ter um conhecimento adequado no domínio das emoções (quando, por exemplo, deve refrear a compaixão).

Pode-se dizer, portanto, que a instituição jurídica se constitui de um sistema de atividades organizadas, executadas por determinados atores, com conhecimento especializado para cumprir o seu papel no subuniverso social de que participam. Subuniversos de significação socialmente separados "resultam de acentuações da especialização dos papéis, levada a um ponto em que o conhecimento específico de um papel torna-se inteiramente esotérico, comparado com o acervo comum do conhecimento" (BERGER \& LUCKMANN, 1985, p. 121).

Segundo Pross (1980), a lei e os tratados estão em representação de relações que se dão mediante elos; estes se perdem, se não forem reconhecidos nem se impuserem sua função simbólica. A lei é o símbolo do poder perante a sociedade; ela simboliza o que "deve" ser em conformidade com o Direito, e o reconhecimento pelos indivíduos é o que a faz valer. Reconhecimento e imposição autoritária constituem a ordem jurídica, na visão de Pross (1980). A certeza de que as relações designadas são corretas mantêm a ordem social. É assim que o Direito Penal, por exemplo, mantém a ordem: a certeza do castigo é o que atemoriza o transgressor da lei, não propriamente a natureza do castigo ${ }^{5}$. E cabe ao juiz, como representante da lei, determinar a punição do transgressor.

\footnotetext{
${ }^{4}$ Há os especialistas do Direito Penal, do Direito Processual, do Direito Civil (vara de família e vara trabalhista), do Direito Ambiental, do Direito Internacional. Mais recentemente, com o advento da Internet, mais um grupo de especialistas dentro do grupo dos operadores de direito está se formando: diante dos chamados "crimes virtuais", a instituição jurídica tem sido desafia a legislar as atividades na rede internacional de computadores. Com isso, uma nova gama de informações e terminologias específicas se forma.

${ }^{5} \mathrm{Na}$ sociedade brasileira, por exemplo, a sensação de impunidade sentida atualmente parece levar indivíduos transgressores a perderem o temor, pois tem-se a impressão de que não há a "certeza do castigo". A conseqüência natural disso é o aumento da criminalidade.
} 
A instituição jurídica, como quaisquer outras instituições, tem caráter controlador. Nesse subuniverso, os "estranhos" têm de ser impedidos de entrar, a fim de que o controle seja mantido. Por outro lado, tal instituição requer privilégios e reconhecimentos especiais da sociedade mais ampla; com isso, existe o problema de manter de fora os estranhos e, ao mesmo tempo, "fazer com que admitam a legitimidade deste procedimento" (LUCKMANN \& BERGER, 1985, p. 120-121). Para isso, "entra em ação uma maquinaria inteira de legitimação, com o fim de manter os leigos como leigos" (Idem, p. 121) e os operadores do Direito como operadores do Direito e, se possível, que ambos assim procedam de maneira satisfatória.

Sobre a relação do grupo dos operadores do direito com os demais grupos sociais, arrisca-se dizer que os primeiros, cujos membros já tiverem passado de uma ordem para outra, são, de acordo com os pressupostos de Elias e Scotson (2000), os estabelecidos, ou seja, os indivíduos que, tendo adquirido e demonstrado os conhecimentos necessários, passam a exercer determinados papéis (advogado, promotor, juiz ou ministro do Superior Tribunal de Justiça, por exemplo). Os outsiders podem ser os indivíduos que, por pertencerem a grupos diferentes, não participam das atividades tipificadas realizadas pelo grupo estabelecido.

Outro mecanismo que parece ser marcante no processo de institucionalização do grupo em análise são os portadores de símbolos. Considerando-se a teoria de Pross, segundo a qual portadores podem ser pessoas transportadas para operar na qualidade de poder físico ou psíquico e representar a atualidade e o caráter imediato do poder que está ausente, pode-se dizer que, na instância jurídica, o oficial de justiça, por exemplo, que cumpre uma diligência determinada pelo juiz, diante do cidadão que está sendo intimado a uma audiência, é um portador de símbolo. Como tal, ele representa a lei diante do cidadão comum, incorpora a competência legítima atribuída pela instituição que ele representa naquele momento.

Do mesmo modo, ao juiz é reconhecida a competência legítima de marcar sua presença (por meio da primeira pessoa do singular, por exemplo) em enunciados que produzem ações específicas, como "Eu decido pela absolvição do réu" (pois só o juiz tem a competência de decidir). Esse mesmo enunciado não teria validade enquanto ato se fosse proferida pelo advogado de defesa do réu. Conforme Bourdieu (1996), do ponto de vista lingüístico, qualquer um pode dizer qualquer coisa, mas, sob o ponto de vista sociológico, nem todo mundo pode afirmar qualquer coisa. Na falta da autoridade requerida, um propósito será apenas fala e não ato.

As propriedades não-lingüísticas também podem ser verificadas nos procedimentos adotados na instituição jurídica. Quanto mais oficial for a situação, mais capaz de impor por si mesma o reconhecimento da legitimidade do modo de expressão dominante. Nesse sentido, a disposição das pessoas no tribunal do júri pode ser visto como um mecanismo de institucionalização: o juiz se posiciona ao centro, de onde comanda a todos, determinando o momento em que as pessoas autorizadas podem falar e mantendo o controle sobre a platéia, que não pode se pronunciar.

O vestuário do juiz também é simbólico. A toga (espécie de capa ou manto, amplo e longo) é "uma informação indicial da função exercida pelo juiz e a cor negra sinaliza seriedade e compostura que devem caracterizá-lo. Não se misturam trajes como não 
se usurpam funções" (DAMIÃO \& HENRIQUES, 1997, p. 19). O vestuário contribui para compor o cenário formal que simboliza o poder de um grupo sobre os outros.

Os advogados também tendem a uniformizar seu vestuário, embora em menor estabilidade que o dos juízes, quando os homens escolhem comparecer ao local de trabalho (escritório, fórum) usando paletó, calça e sapatos em estilo formal, e as mulheres usando saia justa e salto alto (apenas para exemplificar), ambos carregando uma pasta de couro. Esses elementos podem ser analisados segundo a "teoria da classe ociosa", de Veblen (1980). Para esse autor, o vestuário é o que mais põe em evidência perante os observadores a situação pecuniária de quem o usa, mais pela aparência respeitável, do que pela proteção da própria pessoa, além de ser dispendioso (evidência de status principalmente em uma sociedade que valoriza o poder econômico). O vestuário deve tornar visível também que quem o usa não está ligado a qualquer espécie de trabalho produtivo $^{6}$. O efeito agradável de vestuários elegantes e imaculados se deve à sugestão de ócio que trazem, da isenção de contato pessoal com processos industriais. Desse modo, parecem corporificar o status, uma espécie de distinção perante os demais grupos sociais. Esses componentes parecem evidenciar o grau de autoridade concedido ao indivíduo que os utiliza em realizar as ações tipificadas da instituição jurídica.

A figura da mulher que, com os olhos vendados, segura uma balança é, talvez, o símbolo pelo qual os demais grupos sociais mais facilmente identificam a instituição jurídica. O reconhecimento desse artefato pelos demais grupos sociais como símbolo do Direito foi possível graças, provavelmente, à sua aceitação e veiculação, por exemplo, no grupo acadêmico. A utilização desse símbolo pelos estudantes de Direito, para assim se diferenciarem de estudantes de outras áreas, fortaleceu o reconhecimento pela sociedade em geral do grupo dos operadores do Direito como uma organização institucionalizada.

Todos esses mecanismos de institucionalização, de uma forma ou de outra, perpassam os textos produzidos pelos operadores do Direito e predeterminam a forma de expressão lingüística empregada. Cada texto deve inserir-se num sistema de gêneros, que, segundo Bazerman (2004), são parte de processos de atividades socialmente organizadas.

Isso pode ser percebido na obrigatoriedade de certos documentos serem apresentados ao juiz para que se instaure um processo. Num Processo Civil, por exemplo, é exigida uma série de documentos que, numa ordem preestabelecida institucionalmente, formarão os "autos do processo". Assim, para iniciar o processo, é preciso que o requerente produza uma Petição Inicial (também chamada Exordial), na qual se dirigirá ao juiz da Vara Civil (a quem compete o julgamento da ação), apresentando sua qualificação e a da parte requerida, os fatos que motivam a ação, os pedidos e os fundamentos legais que embasam o pedido. Ao juiz que recebe o pedido compete deferir ou indeferir o pedido. No caso de deferimento, a outra parte (o requerido contra quem o autor move ação) é notificado e tem o direito de contestar. Para isso, deve apresentar os contraargumentos aos apresentados na Exordial em uma peça processual denominada Contestação, com base nos fundamentos legais. O juiz recebe a contestação e dá prosseguimento aos demais rituais do processo, ou seja, faz uso da ritualização para controlar a disputa entre os cidadãos e, assim, manter a ordem.

\footnotetext{
${ }^{6}$ Trabalho produtivo é compreendido por Veblen (1980) como aquele que se efetiva no contato pessoal com processos industriais, cuja execução requer esforço físico e/ou movimentos corporais.
} 
Qualquer cidadão comum pode requerer um direito em juízo. Na Constituição Federal do Brasil, consta que é assegurada a todos os cidadãos "o direito de petição aos Poderes públicos em defesa dos direitos ou contra ilegalidade ou abuso de poder" (Cap. I, Art. $5^{\circ}, \mathrm{XXXIV}$, a). No entanto, isso raramente ocorre devido ao desconhecimento, dentre outros aspectos, dos trâmites de um processo judicial e mesmo da legislação, sem contar quão hermética se lhe apresenta a linguagem em que a lei está registrada e a que é empregada pelos membros do grupo com os quais o requerente terá de interagir (já que a eles a sociedade concedeu o poder de decisão, o poder de discernir o justo do injusto).

Daí a necessidade de indivíduos não pertencentes ao grupo dos operadores do Direito contratarem um advogado, ou seja, um profissional que conhece as rotinas da instituição jurídica, compreende a linguagem utilizada e tem autorização ${ }^{7}$ para participar de certas atividades no grupo institucionalizado. $O$ advogado torna-se o representante legal do cidadão comum (autor ou réu do processo) por meio de um instrumento de representação chamado Procuração Ad Judicia. Segundo Damião \& Henriques (1999, p. 165),

Consoante a regra do art. 36 CPC8, só o advogado legalmente habilitado, salvo os casos em que se permite postular em causa própria, pode procurar em juízo. Necessário se faz a procuração, sem a qual não será o advogado habilitado (regularmente inscrito na Ordem dos Advogados e sem impeditivos) admitido como um procurador judicial, art. 37 CPC. Obrigatória a cláusula Ad Judicia para o foro em geral, devendo estar expressos os poderes especiais enumerados no art. 38, CPC.

Os gêneros utilizados pelos operadores que atuam num âmbito não são necessariamente os mesmos, já que a organização das atividades (rotinas) nos subuniversos apresenta algumas diferenças dependendo dos tipos de crimes a serem julgados, que requerem certas especialidades.

No âmbito penal ${ }^{9}$, o julgamento de crime contra a vida é da competência do Direito Penal. As atividades a serem realizadas pelo grupo de operadores do Direito para que, ao final, o juiz decida pela condenação ou absolvição do réu seguem um percurso distinto em alguns aspectos das atividades realizadas em outras varas. A instauração do processo começa com a denúncia do Promotor do Ministério Público, que fundamenta a denúncia nos fatos narrados pelo delegado no relatório de inquérito. As informações contidas nesse relatório advêm de uma série de atividades realizadas por profissionais específicos que registram em textos os dados de suas atividades.

\footnotetext{
${ }^{7}$ No Brasil, essa autorização é concedida pela OAB (Ordem dos Advogados do Brasil), que avalia com rigor os conhecimentos dos bacharéis em Direito, que, aprovados em tal avaliação, passam a ser representados por um número (o número da $\mathrm{OAB}$ ). Esse número lhes dá poder para representar outro indivíduo em juízo.

${ }^{8}$ CPC é sigla para Código de Processo Civil.

${ }^{9}$ As informações apresentadas foram coletadas do Código de Processo Penal e de artigos publicados por profissionais da área de Direito, tais como: Rui Carlos Duarte Bacciotti (Rui Carlos Duarte Bacciotti, professor universitário e diretor técnico de Serviço da $2^{\text {a }}$ Vara Cível da Comarca de Rio Claro-SP), Marlusse Pestana Daher (Promotora de Justiça no Espírito Santo e especialista em Direito Penal e Processual Penal) e Marcus Vinícius Amorim de Oliveira (promotor de Justiça no Ceará, professor de Direito Processual Penal e de Criminologia, mestre em Direito).
} 
Dentre esses profissionais, o médico perito, por exemplo, representante do Instituto Médico Legal, produz o auto de necropsia da vítima, atestando as condições da morte. Os dados que esse profissional apresentar no texto poderão ser utilizados pela acusação ou pela defesa para sustentar suas teses no decorrer do processo. Por isso, o auto de necropsia é documento obrigatório anexado ao relatório do inquérito e deve ser solicitado pelo delegado que investiga o caso. O delegado reúne os depoimentos das partes envolvidas e das testemunhas (declarações), o auto de necropsia, auto de apreensão (do instrumento que tiver sido utilizado para cometer o crime) e demais documentos que a instituição jurídica determinar como necessários para provar a ocorrência de um crime contra a vida, e encaminha ao fórum da região onde o crime aconteceu.

No fórum, o inquérito é distribuído pelo escrivão (que produz uma Certidão) a uma Vara Criminal. O Juiz de Direito dessa Vara, por sua vez, determina abertura de vista ao Promotor de Justiça, o qual, examinando os autos, pode optar por uma das alternativas perante o juiz, a saber: a) devolver à autoridade policial para outras diligências que entender necessária (por meio de um requerimento); b) requerer o arquivamento do inquérito por entender que não há suficientes indícios de autoria, ou que não existe prova da materialidade do crime (por meio de um requerimento); c) oferecer denúncia entendendo provada a materialidade de um crime e a existência de indícios de que alguém identificado o cometeu, arrolando até oito testemunhas.

Outras ações se seguem, até que o juiz decida se o caso deve ser julgado por um júri popular (representantes da sociedade, ou seja, de outros grupos, decidirão se o réu é culpado ou inocente) ou ser arquivado. A Figura 1 apresenta um esquema, elaborado com base em informações obtidas em artigos produzidos por profissionais do Direito ${ }^{10}$ e na análise dos textos que correspondem aos autos do processo penal da $1^{\underline{a}}$ Vara Criminal de Santa Maria-RS.

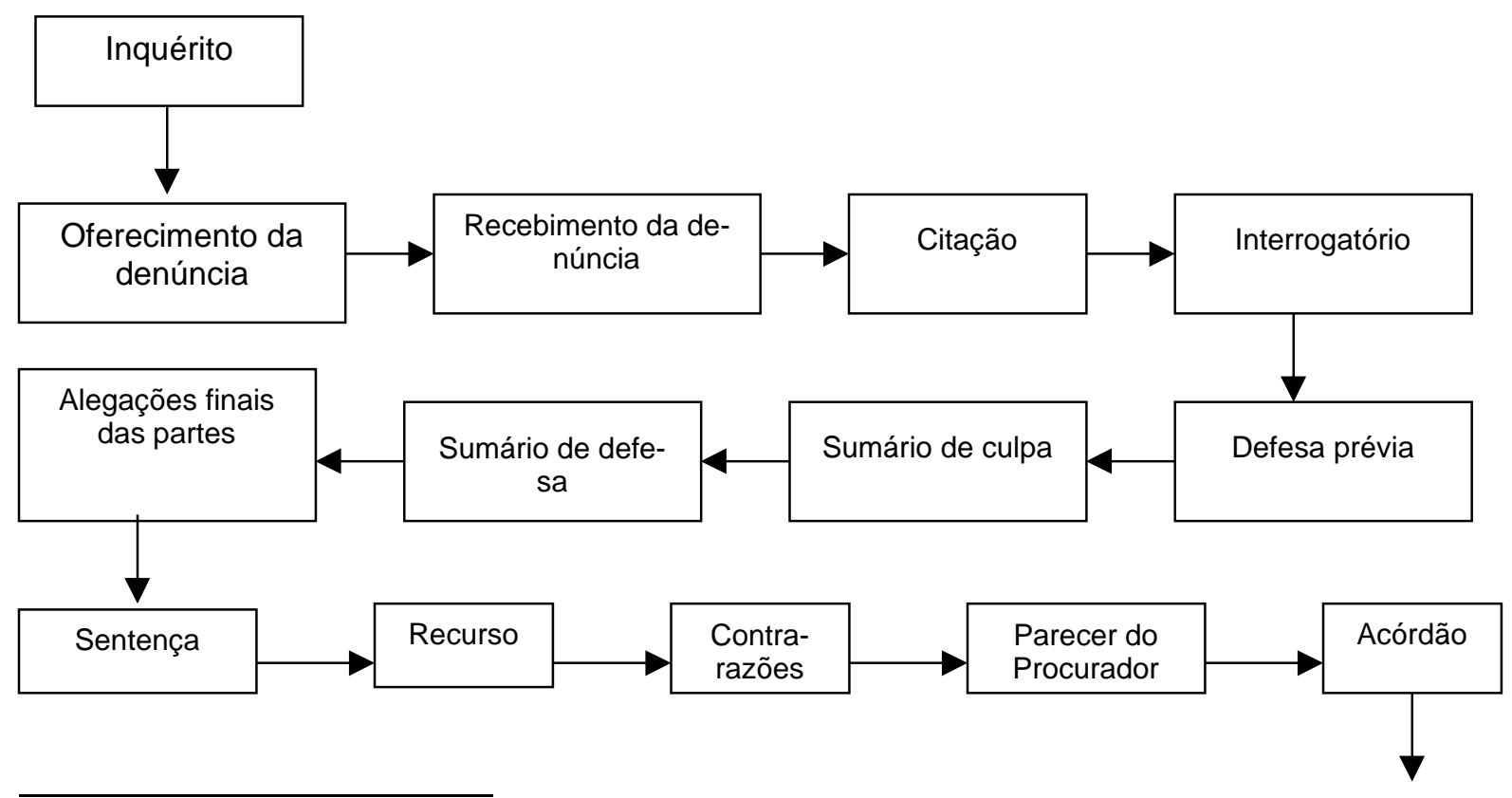

${ }^{10}$ BACCIOTTI, Rui Carlos Duarte. Processo e o Tribunal do Júri no Brasil. Disponível em: http://www1.jus.com.br/doutrina/texto.asp?id=1070. Acesso em: 15 abr. 2005.

DAHER, Marlusse Pestana. 0 júri. Disponível em: http://www1.jus.com.br/doutrina/texto.asp?id-1070. Acesso em: 15 abr. 2005.

OLIVEIRA, Marcus Vinícius Amorim de. 0 julgamento em plenário do Júri Popular. Disponível em: http://www1.jus.com.br/doutrina/texto.asp?id-1070. Acesso em: 15 abr. 2005. 


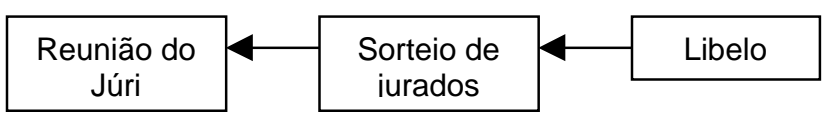

Figura 1 - Esquema do sistema de atividades de um Processo Penal.

Na perspectiva de sistema de atividades proposta por Bazerman (2005), cada profissional atua com um conjunto de gêneros, que configura a conjunto de atividades realizadas. O juiz de Direito, por exemplo, recebe denúncia e determina a citação do denunciado e seu comparecimento à sua presença para ser interrogado por meio de mandados; responde a requerimentos que lhe são endereçados pelas partes (promotoria e defensoria); produz (ou pelo menos assina) ofícios para comunicar ou determinar; interroga o réu em data determinada, redige a sentença em que decide o andamento do processo com base nos autos com as alegações da acusação e da defesa. Nessa ocasião, o juiz poderá:

a) pronunciar o réu, ou seja, reconhecer a presença dos elementos constitutivos do dolo, entendendo provada a materialidade de um crime doloso e a existência de suficientes indícios de autoria, sem aprofundar-se no mérito, remete o julgamento ao Tribunal Popular do Júri;

b) impronunciar o réu (decide pela absolvição do denunciado e julga improcedente a denúncia), caso conclua que não há provas suficientes para incriminar o réu (art. 409);

c) desclassificar a infração para outro crime cujo julgamento não compete ao Tribunal do Júri;

d) absolver sumariamente o réu caso exista prova duvidosa de que ele agiu sobre o amparo de uma excludente de criminalidade (legítima defesa, por exemplo).

A sentença é, sem dúvida, o gênero textual/discursivo em que o juiz realiza sua principal atividade - apresentar sua decisão, justificando-a com base nos autos do processo. Mas a análise de todos os gêneros que compõem um Processo permite perceber que o juiz assume também o papel de intermediário - cabe a ele controlar todo sistema de atividades. Esse é mais um mecanismo que coloca o juiz como representante da lei e, portanto, como o operador que está hierarquicamente acima dos demais membros do grupo.

A partir dessas reflexões, é possível perceber que o uso de certos gêneros, que tipificam as atividades realizadas pelos operadores de direito, ajudam a marcar sua identidade enquanto grupo institucionalizado.

\section{CONSIDERAÇÕES FINAIS}

Os mecanismos que concebem uma instituição reconhecida pelos grupos que formam a rede social são, em linhas gerais, a tipificação recíproca de ações habituais, a historicidade, os papéis e os conhecimentos especializados, as trocas lingüísticas como relações de poder simbólico, os portadores de símbolos e as propriedades não-lingüísticas, bem como o sistema de atividades (ritualização) que propiciam o controle. Os sistemas de atividades manifestam-se em sistemas de gêneros, os quais tipificam as ações do grupo e determinam critérios para a produção e distribuição de textos que circulam no meio social. 
É possível perceber que, com o uso de mecanismos de institucionalização, os operadores do Direito, enquanto grupo institucionalizado, organizam e controlam suas atividades na sociedade, mantendo afastados os indivíduos não pertencentes ao grupo e, ao mesmo tempo, obtendo o reconhecimento dos demais grupos. Assim, a instituição jurídica mantém o poder de decisão e controle das ações em sociedade.

Com base nessas considerações, é possível compreender as razões para a linguagem utilizada nesse grupo ser considerada muitas vezes hermética pelos indivíduos dos demais grupos (leigos). A linguagem "complicada" dos textos que apresentam especificidades de acordo com o sistema de gêneros utilizados é um dos mecanismos que dificulta ao cidadão comum participar do sistema de atividades da instituição jurídica.

$\mathrm{Na}$ realidade, os textos que constituem os autos dos processos jurídicos não podem ser analisados isoladamente; eles fazem parte de uma rede constituída de outros textos, geralmente pertencentes a gêneros diferentes, que, ordenadamente, ajudam a realizar atividades específicas dos participantes do sistema. Para organizar a rede de atividades, em linhas gerais, a instituição jurídica organiza-se em torno das especialidades da Ciência Jurídica, nas quais se fundamentam as varas em que se distribuem os casos a serem julgados pelo Poder Judiciário. Tais varas são: civil, trabalhista, de família, criminal.

Graças a esse e demais mecanismos de institucionalização mobilizados pelo grupo de operadores do Direito, os indivíduos dos demais grupos sociais vêem-se incapacitados de interagir com a instituição que detém o poder de atender o seu pedido. É criada, então, a necessidade de o cidadão comum contratar um advogado, ou seja, um profissional que não só conhece, como também é autorizado a participar do sistema de atividades. Com isso, tem familiaridade com as especificidades dos gêneros que devem ser utilizados para a produção dos textos que ajudarão na realização dessas atividades.

\section{BIBLIOGRAFIA}

BACCIOTTI, Rui Carlos Duarte. Processo e o Tribunal do Júri no Brasil. Disponível em: http://www1.jus.com.br/doutrina/texto.asp?id=1070. Acesso em: 15 abr. 2005.

BAKHTIN, M. Estética da criação verbal. São Paulo: Martins Fontes, 2003. p. 261306. Cap. "Gêneros do discurso".

BAZERMAN, C. Speech Acts, Genres, and Activity Systems: How Texts Organize Activity and People. In: BAZERMAN, C. \& PRIOR, P. (Orgs.). What writing does and how it does it. An introduction to analizing texts and textual practices. Mahwah, NJ: Lawrence Erlbaum Associates, 2004. p. 279-307.

BAZERMAN, C. Gêneros textuais, tipificação e interação. Tradução e organização de Angela Paiva Dionísio e Judith Chambliss Hoffnagel. São Paulo: Cortez, 2005.

BERGER, P. \& LUCKMANN, T. A construção social da realidade. Tradução de Floriano de Souza Fernandes. Petrópolis: Vozes, 1985. 
BOURDIEU, Pierre. A economia das trocas lingüísticas: o que falar quer dizer. Tradução de Sérgio Miceli. São Paulo: Editora da Universidade de São Paulo, 1996.

BRASIL. Constituição da República Federativa do Brasil. Presidência da República, Casa Civil, Subchefia para Assuntos Jurídicos. 1988.

DAMIÃO, R. T. \& HENRIQUES, A. Curso de Português Jurídico. 5. ed. São Paulo: Atlas, 1997.

DAHER, Marlusse Pestana. 0 júri. Disponível em: http://www1.jus.com.br/doutrina/texto.asp?id-1070. Acesso em: 15 abr. 2005.

DAMIÃO, T. D. \& HENRIQUES, A. Curso de Português Jurídico. 5. ed. São Paulo: Atlas, 1997.

ELIAS, N. \& SCOTSON, J. L. Os estabelecidos e os outsiders. Tradução de Vera Ribeiro. Rio de Janeiro: Jorge Zahar Ed., 2000.

FAIRCLOUGH, N. Analysing discourse: Textual analysis for social research. London/New York: Routledge, 2003.

2001.

Discurso e mudança social. Tradução: Izabel Magalhães. Brasília: Ed. UnB,

HEBERLE, V. Análise crítica do discurso e estudos de gênero: subsídios para a leitura e interpretação de textos. In: FORTKAMP, M.; TOMUCTH, L. (Orgs.). Aspectos da Lingüística Aplicada: Estudos em homenagem ao Prof. Hilário Inácio Bohn. Florianópolis: Insular, p. 167-184, 2000.

MEURER, J. L.; MOTTA-ROTH, D. (Orgs.). Gêneros textuais e práticas discursivas. São Paulo: EDUSC, 2002.

MEURER, J. L. Esboço de um modelo de produção de textos. In: MEURER, J. L. \& MOTTA-ROTH, D. (Orgs.). Parâmetros de textualização. Santa Maria: Ed. da UFSM, 1997.

OLIVEIRA, Marcus Vinícius Amorim de. 0 julgamento em plenário do Júri Popular. Disponível em: http://www1.jus.com.br/doutrina/texto.asp?id-1070. Acesso em: 15 abr. 2005.

PROSS, H. Estructura simbólica del poder. Barcelona: Editorial Gili, 1980.

VEBLEN, T. Teoria da classe ociosa. A Alemanha imperial e a revolução industrial. Tradução de Bolívar Lamounier e Olívia Krähebühl. São Paulo: Abril, 1980. 